\title{
Manfaat Senam Hamil Selama Kehamilan Trimester III di Puskesmas Putri Ayu Kota Jambi
}

\author{
Sri Maharani \\ Prodi DIII Kebidanan, STIKes Baiturrahim Jambi \\ Email: maharanibarus@gmail.com
}

Submitted : 12/12/2020

Accepted: 21/06/2021

Published: 28/06/2021

\begin{abstract}
During pregnancy, there will be various changes in the mother, both physiologically and psychologically. These changes are largely due to the influence of hormones, namely the increase in the hormones estrogen and progesterone produced by the corpus luteum which develops into the corpus gravidity and continues its secretion by the placenta after it is fully formed. This causes the mother to feel uncomfortable during pregnancy and triggers stress, which is a sign that the mother is often gloomy. Pregnancy exercise is a form of physical activity that is beneficial because it develops body muscles, increases the elasticity of the pelvic muscles and ligaments and reduces the incidence of bleeding during and after childbirth and can reduce the incidence of fetal distress. Target Output The results of this educational activity on knowledge of physiological changes in pregnant women will also be published in the form of a national scientific journal so that it can be accessed by the public. This community service activity is carried out at the Putri Puskesmas Au Kota Jambi. Implementation time in January 2020. The target in this activity is pregnant women in the third trimester in the work area of the Putri Ayu Community Health Center, Jambi City. The results obtained are that pregnant women are able to understand the benefits of pregnancy exercise. It is recommended that pregnant women participate more frequently in activities that provide knowledge for mothers by attending other health education programs so that they can increase their knowledge.
\end{abstract}

Keywords: pregnant woman, pregnancy exercise

\begin{abstract}
Abstrak
Masa kehamilan akan terjadi berbagai perubahan pada ibu, baik secara fisiologis maupun psikologis. Perubahan tersebut sebagian besar adalah karena pengaruh hormon yaitu peningkatan hormon estrogen dan progesteron yang dihasilkan korpus luteum yang berkembang menjadi korpus graviditas dan dilanjutkan sekresinya oleh plasenta setelah terbentuk sempurna. Hal ini menyebabkan ibu merasa tidak nyaman selama kehamilan dan memicu timbulnya stress yang di tandainya ibu sering murung. Senam hamil merupakan bentuk aktivitas fisik yang bermanfaat karena mengembangkan otot tubuh, meningkatkan elastisitas otot panggul dan ligamentum serta menurunkan kejadian perdarahan selama dan sesudah bersalin serta dapat menurunkan kejadian fetal distress. Target luaran Hasil kegiatan edukasi tentang pengetahuan perubahan fisiologis pada ibu hamil ini juga akan dipublikasikan dalam bentuk jurnal ilmiah nasional sehingga dapat diakses oleh masyarakat. Kegiatan pengabdian kepada masyarakat ini dilaksanakan di puskesmas putri au kota jambi. Waktu pelaksanaan pada bulan Januari 2020. Sasaran dalam kegiatan ini adalah ibu hamil trimester III di wilayah kerja puskesmas Putri Ayu Kota Jambi. Hasil yang diperoleh adalah ibu hamil mampu memahami tentang manfaat senam hamil. Disarankan agar ibu hamil lebih sering mengikuti kegiatan yang memberikan pengetahuan bagi ibu dengan menghadiri penyuluhan kesehatan lainnya sehingga dapat meningkatkan pengetahuan ibu.
\end{abstract}

Kata Kunci: ibu hamil, senam hamil 


\section{PENDAHULUAN}

Kondisi abnormal dalam suatu kehamilan maupun persalinan dapat dicegah dengan mempersiapkan baik secara mental maupun fisik ibu hamil. Menurut profil kesehatan Indonesia tahun 2018, Angka Kematian Ibu (AKI) adalah 305 per 100.000 kelahiran hidup. Tahun 2018 dari hasil pada profil kesehatan Indonesia Angka Kematian Ibu (AKI) di Indonesia menunjukkan angka 305/100.000 Kelahiran Hidup, jauh di atas target untuk Sustainable Development Goals (SDG) pada tahun 2030 yaitu sekitar 70/100.000 Kelahiran Hidup. (Profil Kesehatan Indonesia, 2018).

Tingginya Angka Kematian Ibu terjadi oleh karena komplikasi kehamilan atau persalinan yaitu perdarahan, infeksi yang salah satunya disebabkan oleh persalinan sulit atau lama dan eklamsia. Adapun faktor-faktor yang menyebabkan persalinan lama adalah power yang lemah seperti: his, kontraksi otot dinding perut, kontraksi diafragma pelvik atau kekuatan mengejan, ketegangan dan kontraksi ligamentum rotundum, passenger (kelainan letak janin dan plasenta letak rendah), passage (jalan lahir yang sempit). Salah satu persiapan yang seharusnya dilakukan oleh ibu hamil adalah senam hamil. (Syahrul, 2013)

Kurangnya pergerakan selama kehamilan menjadi perhatian karena wanita prenatal yang tidak melakukan olahraga tidak memberikan banyak manfaat kesehatan. Misalnya, berolahraga selama hamil terkait dengan penurunan risiko preeklampsia, kehamilan, diabetes dan kelahiran prematur, serta peningkatan toleransi rasa sakit, pertambahan berat total lebih rendah dan pertambahan massa lemak lebih sedikit, dan meningkatkan citra diri. Untuk alasan ini, pedoman olahraga AS merekomendasikan bahwa semua wanita sehat harus mendapatkan setidaknya 150 menit aktivitas aerobik intensitas sedang selama seminggu kehamilan.(Gaston dan Cramp, 2011)
Senam hamil merupakan bentuk aktivitas fisik yang bermanfaat karena mengembangkan otot tubuh, meningkatkan elastisitas otot panggul dan ligamentum serta menurunkan kejadian perdarahan selama dan sesudah bersalin serta dapat menurunkan kejadian fetal distress. Senam juga merupakan bentuk metode koping yang dapat menghindarkan terjadinya stress fisik akibat kehamilan, seperti mengurangi kram kaki, dan punggung, meningkatkan kemampuan ibu untuk adaptasi dengan adanya perubahan pada tubuhnya. Oleh karenanya American College of Obstetricans and Gynecologist (ACOG) merekomendasikan senam sebagai upaya preventif pada ibu agar proses kahamilan dan persalinan berjalan secara alamiah, dan mengurangi krisis akibat persalinan.(Syahrul, 2013)

Latihan dalam senam hamil terdiri dari pemanasan, latihan inti, latihan pernafasan dan pendinginan. Gerakangerakan dalam latihan pemanasan bermanfaat untuk meningkatkan oksigen yang diangkut ke otot dan jaringan tubuh, memperlancar peredaran darah, serta mengurangi risiko terjadinya kejang atau luka. Sedangkan tujuan gerakan dalam latihan inti adalah pembentukan sikap tubuh, meregangkan dan menguatkan otot terutama otot yang berperan dalam persalinan serta memperbaiki kerja jantung, pembuluh darah, dan paru dalam mengedarkan nutrisi dan oksigen keseluruh tubuh. Sehingga dapat menurunkan ketidaknyamanan fisik dan mengurangi keluhan-keluhan ibu hamil.(Wahyuni, 2013)

Latihan pernafasan dan pendinginan dalam senam hamil merupakan suatu metode relaksasi. Dimana relaksasi dalam latihan pernafasan dilakukan dengan cara latihan nafas perut (menaikkan perut saat menarik nafas dan mengempiskan perut saat membuang nafas dari mulut secara perlahan), latihan nafas diafragma/iga (hirup nafas melalui hidung sampai iga 
terasa mengembang, kemudian hembusksn nafas melalui mulut), latihan nafas dada (hirup nafas melalui hidung sampai dada terasa mengembang, kemudian hembuskan nafas melalui mulut). Latihan pendinginan dilakukan melalui penegangan otot-otot tertentu selama beberapa detik untuk kemudian dilepaskan. Bila ibu hamil melakukan latihan tersebut dengan benar, akan terasa efek relaksasi pada ibu hamil yang berguna untuk mengatasi kecemasan dan ketegangan yang ia rasakan selama kehamilan berlangsung.(Wahyuni, 2013)

Berdasarkan fenomena diatas penulis tertarik memberikan pengetahuan mengenai senam hamil selama kehamilan trimester III pada ibu hamil.

Tujuan dari kegiatan pengabdian ini yaitu memberikan penyuluhan kesehatan tentang senam hamil pada trimester III kehmailan dengan harapan dapat memberikan kenyamanan pada ibu hamil selama menjalani kehamilan.

Manfaat pengabdian kepada masyarakat yang dilakukan adalah Kegiatan ini memberikan pengalaman yang baik kepada ibu hamil untuk mengatasi keluhan yang terjadi akibat perubahan fisiologi yang terjadi selama kehamilan pada ibu hamil trimester III dengan senam hamil.

\section{TARGET DAN LUARAN}

1. Target

Target dalam kegiatan pengabdian kepada masyarakat unu adalah ibu hamil.

2. Luaran

Adapun luaran kegiatan pengabdian kepada masyarakat ini selain submit pada jurnal ilmiah, yaitu:

a. Pemahaman ibu hamil tentang senam hamil.

b. Serta pemberi kesadaran ibu hamil mengenai pentingnya senam hamil selama hamil trimester III.

\section{METODE PELAKSANAAN}

Kegiatan pengabdian kepada masyarakat dilaksanakan pada bulan Januari 2020 dengan sasaran kegiatan adalah ibu hamil jumlah 10 orang.

Tahapan kegiatan Pengabdian kepada kepada masyarakat meliputi:

Persiapan

1. Sosialisasi: pertemuan dengan bidan penanggung jawab kelas ibu hamil.

2. Mengidentifikasi masalah.

3. Perumusan solusi : Menyampaikan rencana kegiatan kepada pihak puskesmas dengan mengurus surat izi melakkan pengabdian kepada masyarakat.

Pelaksanaan

1. Melakukan pretest (menggali pemahaman ibu hamil tentang senam hamil selama kehamilan)

2. Memberikan pendidikan kesehatan tentang pentingnya senam hamil selama kehamilan pada ibu hamil (pengertian, manfaat, cara melakukan, kelemahan).

3. Monitoring dan Evaluasi

\section{HASIL DAN PEMBAHASAN}

Kegiatan penyuluhan ini bertujuan agar ibu hamil mengetahui tentang pentingnya senam hamil selama kehamilan. Pada pengabdian masyaraat ini dilakukan pendidikan kesehatan kepada ibu hamil mengenai pentingnya senam hamil selama kehamilan. Kegiatan penyuluhan berlangsung kurang lebih 30 menit dan terlaksana dengan tertib dan lancar serta mendapat antusia yang baik dari peserta, maupun puskesmas. Kegiatannya adalah melakukan pendidikan kesehatan berupa penyuluhan tentang senam hamil selama masa kehamilan meliputi pengertian, manfaat, cara melakukan, kelemahan. Ibu hamil cukup memahami dan sangat antusias dalam kegiatan ini, terbukti beberapa ibuibu bertanya khususnya tentang senam hamil bagi kehamilan. 


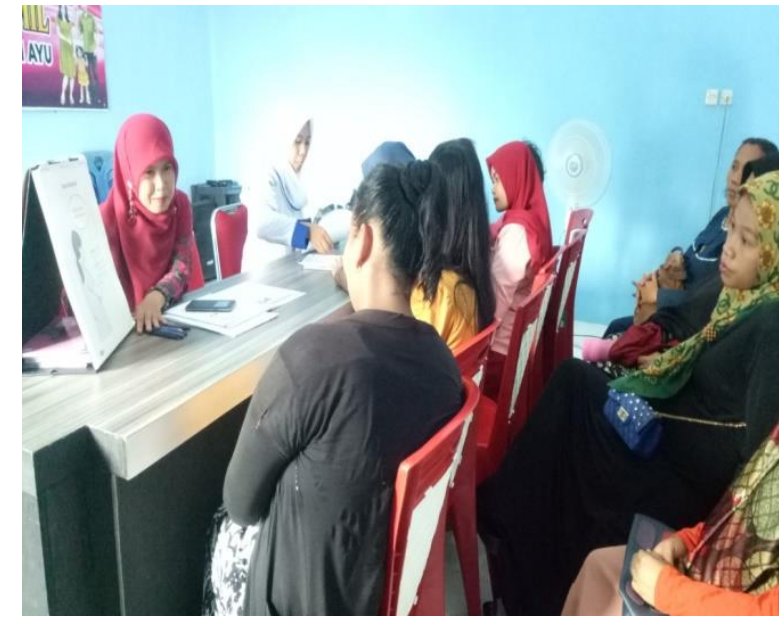

Gambar1. Kegiatan edukasi

Kehamilan merupakan suatu masa yang sangat dinantikan oleh ibu. Dalam kondisi kehamilan terjadi perubahan hormonal dan fisiologis. Perubahan yang terjadi diharapkan dapat dijalani oleh ibu hamil agar menjalani kehamilan dengan nyaman. Perubahan fisiologis dimulai setelah pembuahan dan mempengaruhi sistem organ dalam tubuh. Perubahan yang terjadi mempengaruhi farmakokinetik (penyerapan, distribusi, metabolisme dan eliminasi dan sifat farmakodinamik setiap orang yang berbeda).

Alasan kenapa ibu hamil perlu diberikan informasi tentang senam hamil adalah ibu hamil rasa keingintahuan yang besar dan cenderungingin merasakan kenyamanan selama kehamilan. Perubahan fisiologi yang terjadi selama kehamilan juga mempengaruhi ketidaknyaman yang timbul selama kehamilan. Ibu hamil pertama tidak jarang memiliki pikiran yang mengganggu, sebagai pengembangan reaksi kecemasan terhadap cerita yang diperolehnya.Adanya pikiran-pikiran seperti melahirkan yang akan selalu diikuti dengan nyeri kemudian akan menyebabkan peningkatan kerja sistem syaraf simpatetik.

Dalam situasi ini, sistem endokrin, terdiri dari kelenjar-kelenjar, seperti adrenal, tiroid, dan pituitari (pusat pengendalian kelenjar), melepaskan pengeluaran hormon masing-masing ke aliran darah dalam rangka mempersiapkan badan pada situasi darurat. Akibatnya, sistem syaraf otonom mengaktifkan kelenjar adrenal yang mempengaruhi sistem pada hormon epinefrin. Hormon yang juga dikenal sebagai hormon adrenalin ini memberi tenaga pada individu serta mempersiapkan secara fisik dan psikis. (Wulandari, 2006)

Adanya peningkatan hormon adrenalin dan noradrenalin atau epinefrin dan norepinefrin menimbulkan disregulasi biokimia tubuh, sehingga muncul ketegangan fisik pada diri ibu hamil. Dampak dari proses fisiologis ini dapat timbul pada perilaku sehari-hari. Ibu hamil menjadi mudah marah atau tersinggung, gelisah, tidak mampu memusatkan perhatian, ragu-ragu, bahkan kemungkinan ingin lari dari kenyataan hidup. (Wulandari, 2006)

Kondisi ini dapat menyebabkan kecemasan dan ketegangan lebih lanjut sehingga membentuk suatu siklus umpan balik yang dapat meningkatkan intensitas emosional secara keseluruhan Apabila tidak diberi perhatikan dan dibiarkan tanpa pengawasan, dapat menimbulkan depresi pada ibu hamil. (Wulandari, 2006)

Untuk memutuskan siklus kecemasan tersebut, maka senam hamil sebagai salah satu pelayanan prenatal, merupakan suatu alternatif terapi yang dapat diberikan pada ibu hamil.Senam hamil merupakan latihan gerak yang diberikan pada ibu untuk menjadikan tubuh yang sehat dan bugar. Oleh karena itu, selain makan secara teratur, ibu hamil harus cukup istirahat dan berolahraga sesuai dengan kebutuhannya, salah satu olahraga yang baik untuk ibu hamil adalah senam hamil. Senam hamil merupakan terapi latihan gerak yang diberikan pada ibu hamil untuk mempersiapkan dirinya baik fisik maupun mental dalam menghadapi persalinan. (Wulandari, 2006) 
Hasil penelitian yang dilakukan oleh nila marwiyah dengan judul pengaruh senam hamil terhadap kualitas tidur ibu hamil trimester II dan III dikelurahan Margaluyu Wilayah kerja Puskesmas Kasemen dengan hasil terdapat pengaruh kualitas tidur setelah dilakukan perlakuan senam hamil pada ibu. Tidur yang cukup akan membuat ibu hamil lebih bugar dan sehat sehingga dapat beraktifitas dengan baik, janin yang dikandungnya pun akan tumbuh dengan sehat.(N, Marwiyah, 2018) Selain itu hasil penelitian yang dilakukan oleh Primatia Yogi Wulandari dengan judul "Efektivitas Senam Hamil sebagai Pelayanan Prenatal dalam Menurunkan Kecemasan Menghadapi Persalinan Pertama" didapatkan hasil bahwa ada perbedaan yang signifikan ibu hamil yang diberikan senam hamil antara kelompok eksperimental dan control dalam menurunkan kecemasan menghadapi persalinan pertama dengan $p<0,05$.

\section{KESIMPULAN DAN SARAN}

\section{Kesimpulan}

Pelaksanaan pengabdian kepada mayarakat khususnya ibu hamil di wilayah kerja Puskesmas Putri Ayu Kota Jambi yang dilakukan oleh dosen Sekolah Tinggi Ilmu Kesehatan Baiturahim Jambi berjalan dengan baik. Ibu hamil yang hadir antusias dalam membaca leaflet yang diberikan dan bertanya apa yang mereka belum mengerti. Kegiatan ini memberikan pengalaman yang baik kepada ibu hamil untuk mengatasi keluhan yang terjadi akibat perubahan fisiologi yang terjadi selama kehamilan pada ibu hamil trimester III dengan senam hamil.

\section{Saran}

Agar lebih sering mengikuti kegiatan yang memberikan pengetahuan bagi ibu dengan menghadiri penyuluhan kesehatan lainnya sehingga dapat meningkatkan pengetahuan ibu.

\section{UCAPAN TERIMAKASIH}

Terima kasih saya ucapkan kepada STIKes Baiturrahim Jambi yang memberikan support dan memberikan pendanaan dalam pelaksanaan pengabdian masyarakat. Selain itu terima kasih pula kepada instansi tempat pelaksanan atas kerjasamanya.

\section{DAFTAR PUSTAKA}

Gaston, A. dan Cramp, A. (2011) "Exercise during pregnancy: A review of patterns and determinants," Journal of Science and Medicine in Sport. Sports Medicine Australia, 14(4), hal. 299-305.

doi: 10.1016/j.jsams.2011.02.006.

Syahrul, F. (2013) "Pengaruh Senam Hamil Terhadap Proses Persalinan Dan Status Kesehatan Neonatus Pregnancy Exercise Infl uence In Labor And Neonatal Health Status," hal. 316-324.

Wahyuni, layinatul N. (2013) "Manfaat Senam Hamil Untuk Meningkatkan Durasi Tidur Ibu Hamil," KESMAS Jurnal Kesehatan Masyarakat, 8(2), hal. 128-136. doi: 10.15294/kemas.v8i2.2638.

Wulandari P. (2006). "Efektivitas Senam Hamil sebagai Pelayanan Prenatal dalam Menurunkan Kecemasan Menghadapi Persalinan Pertama" INSAN. Fakultas Psikologi Universitas Airlangga. Vol.8 No.2. 